UDK: 331.45/.46

DOI: https://doi.org/10.24867/09HZ02Stajic

\title{
PRIMENA VLAŽNOG POSTUPKA ODSUMPORAVANJA DIMNIH GASOVA NA PRIMERU TERMOELEKTRANE UGLJEVIK
}

\section{APPLICATION OF THE WET FLUE GAS DESULPHURISATION PROCEDURE IN THE EXAMPLE OF THE UGLJEVIK THERMAL POWER PLANT}

\begin{abstract}
Smiljana Stajić, Zoran Čepić, Fakultet tehničkih nauka, Novi Sad
\section{Oblast - ZAŠTITA ŽIVOTNE SREDINE}

Kratak sadržaj - u okviru rada predstavljen je problem prekograničnih vrijednosti emisije sumpornih oksida $u$ Termoelekrani Ugljevik, kao i instaliranje postrojenja za odsumporavanje dimnih gasova i smanjenje emisija.

Ključne reči: Termoelektrana Ugljevik, emisija sumpornih oksida, odsumporavanje dimnih gasova, vlažni postupak.

dioksid prelazi u sulfatnu kiselinu koja se padavinama deponuje na tlo, što može da dodvede do promjene kiselosti vodenih ekosistema i zemljišta, što je od velike važnosti za Semberiju koja je značajno poljoprivredno područije.

Da bi se riješio problem visokog sadržaja sumpornih oksida u dimnim gasovima, instalirano je postrojenje za odsumporavanje dimnih gasova.
\end{abstract}

Abstract - the issue of transboundary sulfur dioxide emision values at the Ugljevik Thermal Power Plant was presented, as well as the installation of flue gas desulphurisation plants and emissiom reductions.

Keywords: Ugljevik Thermal Power Plant, sulfur dioxide emissions, flue gas desulphurization, wet scrubber.

\section{UVOD}

Opština Ugljevik se nalazi u sjevero-istočnom dijelu Republike Srpske i Bosne i Hercegovine, na istočnim padinama planine Majevice prema najvećoj žitnici u Bosni Hercegovini, Semberiji. Površina zemljišta koja se koristi u kompleksu Termoelektrane Ugljevik iznosi 61 ha 11 ari i $65 \mathrm{~m}^{2}$ [1]. Termoelektrana Ugljevik je najveći gigant u regiji.

Njena osnovna dijelatnost je proizvodnja uglja i električne energije, mada pored navedenih ima i desetak pridruženih delatnosti. TE Ugljevik broji oko 2000 zaposlenih i, pored toga što predstavlja zamajac ekonomskog i privrednog razvoja regije, takođe predstavlja i najvećeg zagađivača životne sredine regije, što je posledica samog procesa proizvodnje. Termoelektrana Ugljevik kao energent koristi mrki ugalj sa visokim sadržajem gorivog sumpora u sebi, tako da je emisija sumpor-dioksida u atmosferu velika.

U dimnim gasovima sadržaj sumpor-dioksida se kreće oko $20.000 \mathrm{mg} / \mathrm{Nm}^{3}$ [2]. Ove koncentracije značajno prevazilaze dozvoljene zakonske vrednosti. Zakonska regulativa Rep. Srpske, BiH, kao i Evropske Unije dopuštaju emisiju sumpor-dioksida u dimnom gasu do $400 \mathrm{mg} / \mathrm{Nm}^{3}$ [3], što je 50 puta manje od emitovanih vrednosti, tako da je imperativ smanjenje emisije sumpor-dioksida, odnosno neophodno je izvršiti odsumporavanje dimnih gasova. Zbog korišćenja visokog dimnjaka od oko 310 m, emitovani dimni gasovi koji nose sumpor-dioksid se transportuju preko granica $\mathrm{BiH}$, stvarajući imisione prekogranične probleme. Hemijskom transformacijom, sumpor-

\section{NAPOMENA:}

Ovaj rad je proistekao iz master rada čiji mentor je bio doc. dr Zoran Čepić.

\section{GORIVO TERMOELEKTRANE UGLJEVIK}

Pogonsko gorivo TE Ugljevik je mrki ugalj. Otkop i utovar uglja se vrši hidrauličnim bagerima, a odvoz do industrijskog platoa obavlja se kamionima damperima.

$\mathrm{Na}$ industrijskom platou vrši se drobljenje uglja, najprije $u$ primarnoj drobilici do granulacije od $450 \mathrm{~mm}$, a zatim u sekundarnoj drobilici do granulacije $40 \mathrm{~mm}$, i u toj granulaciji i stiže u elektranu. Nakon drobljenja se ugalj trakastim transporterima transportuje do deponnije uglja $u$ krugu elektrane.

\subsection{Analiza uglja}

Uzorci uglja se uzimaju svakodnevno sa depoa 1, 2, 3 ili 4, u zavisnosti od toga na koji depo je ugalj odlagan. Pored depoa, uzorkuje se i ugalj sa dodavača koji se nalaze u glavnom pogonskom objektu. U laboratoriji za analizu goriva TE Ugljevik radi se analiza uglja koja obuhvata ispitivanja na sledeće sadržaje:

$>$ Vlaga (Wu, Whi Wg, \% ),

$>\operatorname{Pepeo}(\mathrm{A}, \%)$,

$>$ Ugljen-dioksid $\left(\mathrm{CO}_{2}, \%\right)$,

$>$ Ukupni sumpor $\left(\mathrm{S}_{\mathrm{u}}, \%\right)$,

$>$ Sagorivost u pepelu i šljaci $\left(\mathrm{S}_{\mathrm{m}}, \%\right)$,

$>$ Toplona moć $(\mathrm{H}, \mathrm{KJ} / \mathrm{kg})$.

Za analizu uglja se primjenjuje nekoliko metoda:

$>$ Gravimetrijska,

$>$ Apsorpciona,

$>$ Taložna i

$>$ Sagorijevanje [4].

\section{TEHNIČKO-TEHNOLOŠKE CIJELINE TERMOELEKTRANE UGLJEVIK}

Termoelektrana se sastoji iz šest tehnoloških grupa:

1) Tehnološka grupa I - Glavni pogonski objekat

2) Tehnološka grupa II - Vodosnabdevanje

3) Tehnološka grupa III - Razvodno postrojenje 
4) Tehnološka grupa IV - Gorivo

5) Tehnološka grupa V - Šljaka i pepeo

6) Tehnološka grupa VI - Prateći objekti

$\mathrm{Na}$ osnovu niza zaštitnih mjera koje su propisane zakonom, visina dimnjaka je $310 \mathrm{~m}$, računajući od kote terena (Slika 1.) Dimnjak TE Ugljevik najviša je građevina $u$ $\mathrm{BiH}[1]$.

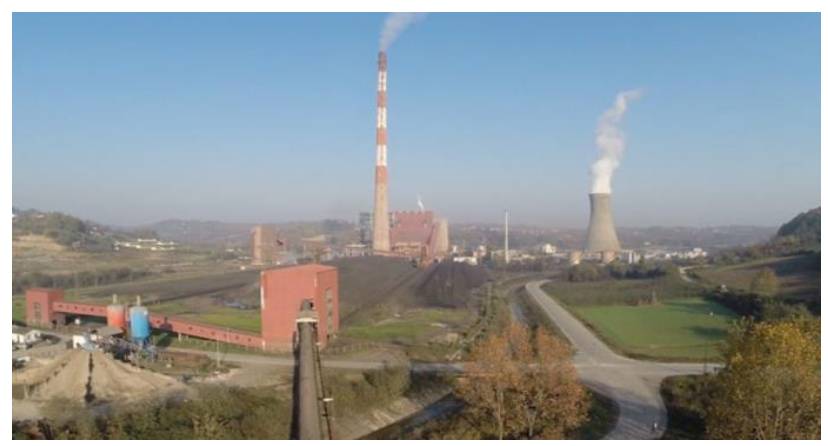

Slika 1. Dimnjak Termolelektrane Ugljevik [1]

\section{ODSUMPORAVANJE DIMNIH GASOVA}

Postrojenje za odsumporavanje dimnih gasova (ODG) se gradi u postojećem industrijskom krugu TE Ugljevik, neposredno uz dimnjak (Slika 2.). Proces odsumporavanja dimnih gasova zahtjeva utrošak krečnjaka. Vode koje će nastajati od procesa odsupmporavanja dimnih gasova, obradjivaće se u postojećem postrojenju za obradu otpadnih voda u Termoelektrani.

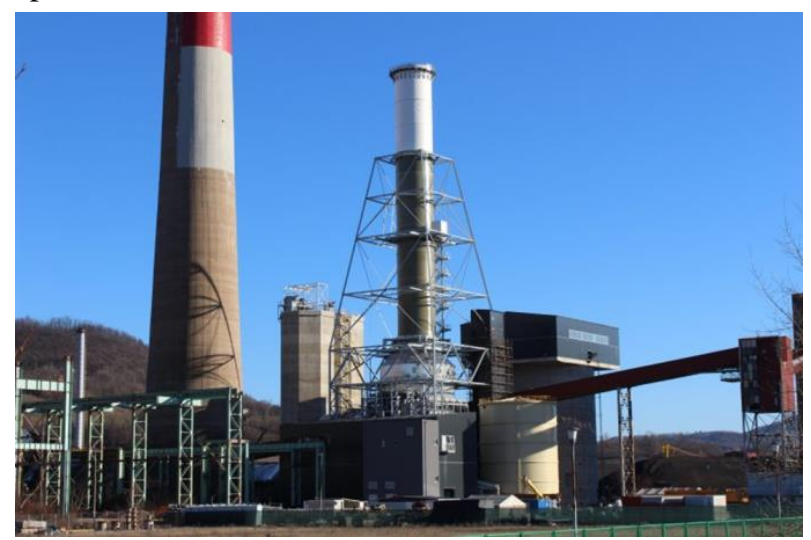

Slika 2. Postrojenje za ODG u izgradnji [1]

Izabran je vlažni postupak odsumporavanja dimnih gasova. Najvažnija komponenta postrojenja je apsorber, gdje se vrše hemijske reakcije kako bi se osiguralo da je $\mathrm{SO}_{2}, \mathrm{HCl}, \mathrm{HF}$ i određena količina $\mathrm{SO}_{3}$ uklonjena iz dimnih gasova.

Nakon što se leteći pepeo eliminiše iz dimnih gasova u elektrofilterskom postrojenju, dimni gasovi idu u postrojenje za odsumporavanje dimnih gasova, gdje se apsorbent raspršuje u dimne gasove. Krečnjak pogodne granulacije se koristi kao apsorbent u ovim reakcijama, a kao proizvod samog procesa dobija se gips.

Spoljašnji uslovi u kojima postrojenje za odsumporavanje dimnih gasova treba da bude operativno su sledeći:

$>$ Temperatura vazduha: $\min .-30{ }^{\circ} \mathrm{C}, \max .45^{\circ} \mathrm{C}$,

$>$ Brzina vjetra: $0-20 \mathrm{~m} / \mathrm{s}$,

$>$ Relativna vlažnost vazduha: 15 - 100\%,

$>$ Nivo buke: $95 \mathrm{~dB}$ (A) ili manje (ukoliko je udaljenost od mašine $1 \mathrm{~m}$ ),
Seizmički koeficijent: 7+1 MCS i

$>$ Postojeći dimnjak : visina 310 m (unutrašnji prečnik $9,5 \mathrm{~m})$ [2].

\subsection{Glavni fizičko-hemijski procesi odsumporavanja dimnih gasova}

Glavne hemijske reakcije vlažnog postupka odsumporavanja su:

$\mathrm{U}$ kontaktnoj zoni $\mathrm{SO}_{2}$ prelazi iz gasne faze (gas) $\mathrm{u}$ vodeni rastvor (aq):

$\mathrm{SO}_{2}(\mathrm{~g})+\mathrm{H}_{2} \mathrm{O} \rightarrow \mathrm{HSO}_{3}^{-}(\mathrm{aq})+\mathrm{H}^{+}(\mathrm{aq})$

Formirani vodonikovi joni reaguju sa prethodno rastvorenim krečnjakom:

$\mathrm{H}^{+}(\mathrm{aq})+\mathrm{CaCO}_{3}(\mathrm{aq}) \rightarrow \mathrm{HCO}_{3}^{-}(\mathrm{aq})+\mathrm{Ca}^{2+}(\mathrm{aq})$

Nastali joni bikarbonata $\mathrm{i}$ bisulfitni joni reaguju direktno $i$ nastaje kalcijumsulfit:

$$
\begin{aligned}
& \mathrm{HCO}_{3}{ }^{-}(\mathrm{aq})+\mathrm{HSO}_{3}{ }^{-}(\mathrm{aq}) \rightarrow \mathrm{SO}_{3}{ }^{2-}(\mathrm{aq})+\mathrm{H}_{2} \mathrm{O}+\mathrm{CO}_{2} \\
& \mathrm{SO}_{3}{ }^{2-}(\mathrm{aq})+\mathrm{Ca}^{2+}(\mathrm{aq}) \rightarrow \mathrm{CaSO}_{3}(\mathrm{aq})
\end{aligned}
$$

Samo mala količina nastalog kalcijumsulfita prelazi $\mathrm{u}$ talog (s):

$$
\mathrm{CaSO}_{3}(\mathrm{aq})+0,5 \mathrm{H}_{2} \mathrm{O} \rightarrow \mathrm{CaSO}_{3} \cdot 0,5 \mathrm{H}_{2} \mathrm{O}(\mathrm{s})
$$

Aeracija suspenzije u donjem dijelu apsorbera uglavnom rezultira u konverziji kiseonika iz gasne faze u rastvoreno stanje:

$\mathrm{O}_{2}(\mathrm{~g})+\mathrm{H}_{2} \mathrm{O} \rightarrow \mathrm{O}_{2}(\mathrm{aq})+\mathrm{H}_{2} \mathrm{O}$

Paralelno sa tim, čvrst kalcijumkarbonat se rastvara $u$ vodi:

$\mathrm{CaCO}_{3}(\mathrm{~s})+\mathrm{H}_{2} \mathrm{O} \rightarrow \mathrm{CaCO}_{3}(\mathrm{aq})+\mathrm{H}_{2} \mathrm{O}$

Preostali bikarbonatni i bisulfitni joni pretežno reaguju, odnosno oksiduju zajedno sa rastvorenim kiseonikom $\mathrm{u}$ suspenziji i proizvode kalcijumsulfat:

$\mathrm{HCO}_{3}{ }^{-}(\mathrm{aq})+\mathrm{HSO}_{3}{ }^{-}(\mathrm{aq})+0,5 \cdot \mathrm{O}_{2}(\mathrm{aq}) \rightarrow \mathrm{SO}_{4}{ }^{2-}(\mathrm{aq})+$ $\mathrm{H}_{2} \mathrm{O}+\mathrm{CO}_{2}(\mathrm{~g})$

$\mathrm{SO}_{4}{ }^{2-}(\mathrm{aq})+\mathrm{Ca}^{2+}(\mathrm{aq}) \rightarrow \mathrm{CaSO}_{4}(\mathrm{aq})$

$\mathrm{CaSO}_{4}(\mathrm{aq})+2 \mathrm{H}_{2} \mathrm{O} \rightarrow \mathrm{CaSO}_{4} \cdot 2 \mathrm{H}_{2} \mathrm{O}(\mathrm{s})$

Sulfitni joni koji su $\mathrm{u}$ međuvremenu formirani $\mathrm{u}$ suspenziji, takođe $u$ reakciji sa kiseonikom daju bisulfitne jone:

$$
\begin{aligned}
& \mathrm{SO}_{3}{ }^{2-}(\mathrm{aq})+\mathrm{H}_{2} \mathrm{O} \rightarrow \mathrm{HSO}_{3}{ }^{-}(\mathrm{aq})+\mathrm{OH}^{-}(\mathrm{aq}) \\
& \mathrm{HSO}_{3}{ }^{-}(\mathrm{aq})+0,5 \cdot \mathrm{O}_{2}(\mathrm{aq}) \rightarrow \mathrm{SO}_{4}{ }^{2-}(\mathrm{aq})+\mathrm{H}^{+}(\mathrm{aq}) \\
& \mathrm{H}^{+}(\mathrm{aq})+\mathrm{OH}^{-}(\mathrm{aq}) \rightarrow \mathrm{H}_{2} \mathrm{O}
\end{aligned}
$$

Različite faze reakcija se odvijaju istovremeno i kontinuirano. U toku reakcija, vrši se kontinuirana potrošnja apsorbenta krečnjaka, a kao produkt odsumporavanja dobija se gips. Iz tog razloga, pored apsorbera, važno je i samo projektovanje objekta za rukovanje sa krečnjakom i objekta za rukovanje gipsom. Za proces odsumporavanja potrebno je takođe isporučiti i dovoljne količine vode, sa ciljem da se realizuju sve hemijske reakcije.

Dimni gasovi koji izlaze iz apsorbera zasićeni su vodenom parom i koncentracija polutanata je usklađena sa propisima, tako da se mogu emitovati preko vlažnog 
dimnjaka u okolinu. Efikasnost procesa odsumporavanja zavisi od više parametara: kvalitet i granulacija krečnjaka, gustina suspenzije, $\mathrm{pH}$ suspenzije, koncentracija sulfita i kiseonika u suspenziji itd [5].

\subsection{Sistemi i objekti postrojenja odsumporavanja}

Postrojenje odsumporavanja dimnih gasova po vlažnom postupku (Slika 3.) sa krečnjakom ima četiri glavna sistema, a to su:

$>$ Sistem dimnih gasova:

- sistem dimnih gasova.

Sistem apsorbera:

- sistem apsorpcije,

- recirkulacioni sistem apsorbera,

- sistem vazduha za oksidaciju,

- sistem pomoćnog rezervoara i drenaže.

$>$ Rukovanje krečnjakom:

- sistem za prijem, transport i skladištenje krečnjaka,

- sistem za mljevenje krečnjaka,

- sistem za suspenziju krečnjaka.

Rukovanje gipsom, uključujući i tretman otpadnih voda ODG:

- sistem ispuštanja gipsa,

- isušivanje gipsa,

- sistem filtriranja vode,

- sistem transporta i skladištenja gipsa,

- sistem pražnjenja i drenaže,

- sistem procesne vode,

- sistem obrade otpadnih voda sistema ODG,

- sistem komprimiranog vazduha [2].

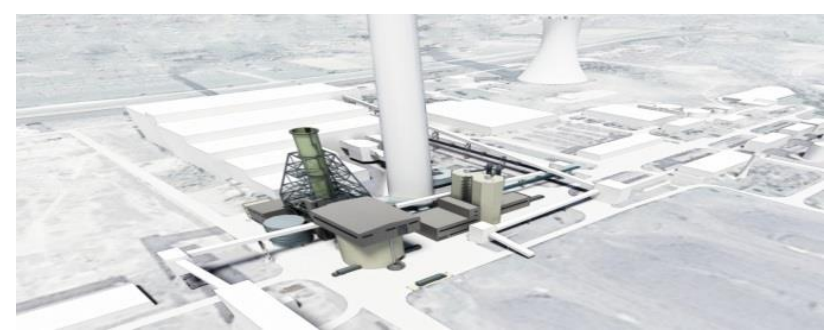

Slika 3. Objekti ODG postrojenja [1]

\subsection{Princip rada postrojenja za odsumporavanje dimnih gasova}

Suspenzija krečnjaka se skladišti u dva rezervoara zapremine $175 \mathrm{~m}^{3}$. Pomoću ugrađenih miješalica suspenzija krečnjaka se kontinuirano mješa, kako bi se spriječilo taloženje čvrstih čestica. Suspenzija krečnjaka se doprema $\mathrm{u}$ apsorber pomoću centrifugalnih pumpi. U sistemu dopreme suspenzije krečnjaka $\mathrm{u}$ apsorber ugrađene su dvije centrifugalne pumpe sa promjenljivim brzinama. Apsorber se sastoji od komore za prskanje u gornjem dijelu i reakcionog rezervoara na dnu.

Dimni gasovi ulaze u donji dio otvorene komore apsorbera pod određenim uglom i brzinom, kako bi poremećaji u struji dimnih gasova $\mathrm{u}$ apsorberu bili što manji. $\mathrm{SO}_{2}$ i drugi zagađivači su uklonjeni kako dimni gasovi struje kroz zonu raspršivanja. Kapljice su prikupljene iz dimnih gasova, kako prolaze kroz eliminatore kapljica. Kao apsorbent koristi se krečnjak koji se u apsorber dodaje u obliku suspenzije. Suspenzija krečnjaka se priprema u sistemu mljevenja krečnjaka.

Gasovi se ispiraju sa suspenzijom gasa i krečnjaka, a sama suspenzija se prska kroz mlaznice koje su postavljene u 6 odvojenih nivoa prskanja. Suspenzija, uz pomoć recirkulacionih pumpi, cirkuliše iz donjeg dijela apsorbera do mlaznica za raspršivanje u svakom nivou raspršivanja. Mlaznice se potpuno prazne gravitacionim dijelovanjem. Dodavanje suspenzije krečnjaka zavisi od koncentracije $\mathrm{SO}_{2} \mathrm{u}$ dimnim gasovima, gustine i $\mathrm{pH}$ vrednosti suspenzije $u$ donjem dijelu apsorbera. Suspenzija sa velikim dijelom gipsa se iz dna apsorbera odvodi prema sistemu za isušivanje gipsa pomoću pumpi za ispuštanje suspenzije gipsa iz apsorbera.

Bočne miješalice $u$ donjem dijelu apsorbera zadržavaju talog u stanju suspenzije. Odvodni ventili apsorbera omogućavaju apsorberu da se potpuno isprazni do područija drenažne jame apsorbera. Pražnjenje apsorbera se izvodi pumpama za ispuštanje suspenzije gipsa iz apsorbera. Suspenzija gipsa se potom distribuira u stanicu za prijem podijeljena na razrijeđeni i gusto koncentrisani dio. Razređeni dio izlazi preko preliva, a gusti dio teče pomoću gravitacije na vakuumski trakasti filter.

Gusta suspenzija se dalje isušuje na vakuumskom trakastom filteru, gdje je raspoređena na filter platnu, odakle se izdvaja voda pomoću vakuuma. Odvojena voda iz vakuum pumpe uskladištena je u rezervoaru za pranje platna. Filterski kolač se nakuplja na filter platnu kao nusproizvod gipsa i propušta se kroz lijevak za pražnjenje, nakon čega se gips isušuje. Isušeni gipsani kolač se skladišti u silos gipsa.

U slučaju da se gips ne može transportovati u silos, reverzibilni transporter sa gumenom trakom šalje isušeni gips na vanjski skladišni prostor.

\section{ZAKLJUČAK}

Rudnik i Termoelektrana Ugljevik emituju polutatnte $\mathrm{u}$ životnou sredinu u značajnim količinama. Vrijednosti emisija premašuju dozvoljene granice, kako standarda Republike Srpske i Bosne i Hercegovine, tako i Evropske Unije. Trenutno najveći problem jeste sumpor dioksid koji nastaje u samoj proizvodnji. Da bi se riješio problem, TE Ugljevik je izgradila postrojenje za odsumporavanje dimnih gasova kojim će smanjiti emisije.

Proces odsumporavanja nema negativni uticaj na kvalitet vazduha, šta više, zahvaljujući odsumporavanju, smanjiće se količine sumpora u dimnom gasu.

Instaliranje postrojenja doprinosi ispunjenju zahtjeva Evropske Unije o dozvoljenim emisijama. Otpadne vode koje nastaju u samom procesu sadrže hloride, sulfate i opasne fluoride, međutim, prije samog ispuštanja vode iz procesa u rijeku Mezgraju, vrši se tretman otpadnih voda.

Ukoliko se sa nusproizvodima, kao i proizvodima koji se koriste u samom proces odsumporavanja upravlja po projektu, neće biti negativnih uticaja na floru, faunu i 
ekosistem. Naseljena mjesta su znatno udaljena od postrojenja za odsumporavanje, tako da je uticaj od buke i vibracija zanemarujući.

Gips koji nastaje kao nusproizvod od procesa odsumporavanja koristi se u mnogobrojne svrhe, tako da bi se vremenom mogla ostvariti i ekonomska dobit, kako od sirovog gipsa koji nastaje, tako i od prerađenog gipsa.

\section{LITERATURA:}

[1] Stojanović B. i dr., Studija izvodljivosti o izgradnji sistema odsumporavanja dimnog gasa na Termoelektrani Ugljevik u RS, 2008.

[2] lančišar K. i dr., Tehnički izvještaj, Postrojenje za odsumporavanje dimnih gasova u Termoelektrani Ugljevik, RUDIS d.o.o Trbovlje, 2017.

[3] **Pravilnik o graničnim vrijednostima emisije zagađujućih materija u zrak, Službene novine Federacije BiH, broj: 33/03

[4] **ZP RiTE Ugljevik, Izveštaj o ispitaivanju uglja, pepela i šljake, Ugljevik, 2019.

[5] Čolić N., Diplomski rad: Idejno rešenje postrojenja za odsumporavanje dimnih gasova na TE „Nikola Tesla B“, Mašinski fakultet, Univerzitet u Beogradu, 2011.

\section{Kratka biografija:}

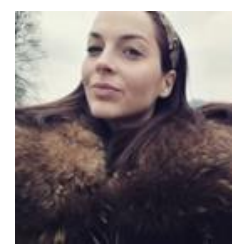

Smiljana Stajić, rođena je u Bijeljini 16.05.1993. godine. Diplomirala je na Fakultetu tehničkih nauka u Novom Sadu 13 06. 2017. godine smijer Inženjerstvo zastite žiotne sredine.

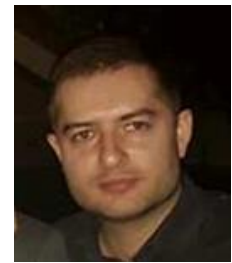

Zoran Čepić je osnovne i master studije završio 2008. godine, na Fakultetu tehničkih nauka, smer Mašinstvo - Toplotna tehnika. Doktorirao je 2018. godine na Departmanu za inženjerstvo zaštite životne sredine $\mathrm{i}$ zaštite na radu, gde je zaposlen kao docent. 